\title{
A quantum chemical study on the magnetic nanocarrier-tirapazamine drug delivery system
}

\author{
S. Avarand, A. Morsali, M. M. Heravi, S. A. Beyramabadi \\ Department of Chemistry, Mashhad Branch, Islamic Azad University, Mashhad, Iran \\ sadaf.avarand@gmail.com, almorsali@yahoo.com,drmh45@yahoo.com,abeyramabadi@gmail.com
}

PACS 78.67.-n, 78.67.Ch

DOI 10.17586/2220-8054-2021-12-2-167-174

\begin{abstract}
Magnetic nanoparticles are among the most important carriers for the delivery of anticancer drugs. Four important noncovalent interactions between tirapazamine anticancer drug (TPZ) and magnetic nanoparticle $\mathrm{Fe}_{6}(\mathrm{OH})_{18}\left(\mathrm{H}_{2} \mathrm{O}\right)_{6}(\mathrm{MNP})$ have been examined by using density functional theory (DFT). Important interactions are those where the drug approaches the magnetic nanocarrier via $\mathrm{NH}_{2}$ (MNP/TPZ1), NO (MNP/TPZ2-3) and intraring N-atom (MNP/TP4) functional groups. The negative values of binding energies and quantum molecular descriptor showed that these interactions contribute to the stability of the system. By increasing the temperature, TPZ can bond to $\mathrm{MNP}$ through $\mathrm{NH}_{2}\left(\mathrm{NH}_{2}\right.$ mechanism), $\mathrm{NO}$ (NO mechanisms) and intraring $\mathrm{N}$-atom ( $\mathrm{N}$ mechanism) functional groups. The activation parameters of four mechanisms were evaluated using quadratic synchronous transit method. Relative energies indicate that the product of the $\mathrm{NH}_{2}$ mechanism is more stable but is produced more slowly (thermodynamic product). In contrast, the products of the NO mechanisms are kinetic products.
\end{abstract}

Keywords: magnetic nanoparticles, tirapazamine, DFT, noncovalent interactions, reaction mechanism.

Received: 15 August 2020

Revised: 19 January 2021

\section{Introduction}

Magnetic nanoparticles have shown significant applications in chemical, biological and drug delivery systems [17]. These nanoparticles include iron, cobalt and nickel elements and their oxides, among which iron oxide nanoparticles are the most widely used. In addition to advantages such as high surface area to volume ratio and unique electronic and chemical properties, iron oxide nanoparticles, due to their magnetic properties, can be targeted to the cancerous tissue by an external magnetic field [8-12]. Once the drug reaches the target tissue, it is released by factors such as temperature, $\mathrm{pH}$ and enzymatic activity [13,14]. In spite of modern methods based on the use of nanocarriers [15-19], traditional chemotherapy methods have many side effects [20,21].

Maghemite $\left(\gamma-\mathrm{Fe}_{2} \mathrm{O}_{3}\right)$ and Magnetite $\left(\mathrm{Fe}_{3} \mathrm{O}_{4}\right)$ nanoparticles are most commonly used in drug delivery systems. Iron oxide nanoparticles have been used to deliver anti-cancer drugs like 5-flurouracil [22], cisplatin [23], camptothecin [24], doxorubicin [25], methotrexate [26], tamoxifen [27], paclitaxel [28], sorafenib [29], gemcitabine [30], 6-mercaptopurine [31] and mitoxantrone [32] to the target tissue. These nanoparticles have also been used along with other carriers such as gold [33], chitosan [34], silica [35], carbon nanotubes [36], surfactant [37], $\mathrm{C}_{60}$ [38], peptide nanotubes [39],lipid [40], liposome [41], dextran [42], polymers [43,44] and DNA [45].

Quantum chemical calculations have been widely used to investigate drug delivery systems from a molecular point of view [46-53]. In this work, quantum mechanics was used to investigate a drug delivery system, including iron oxide nanoparticles and 1,3-amino-1,2,4-benzotriazine-1,4-N,N-dioxide (tirapazamine). Tirapazamine is an anticancer drug used to treat neck cancer, head cancer, cervical cancer and prostate cancer $[54,55]$. Such computations can inspire scientists to manufacture new systems for drug delivery.

\section{Computational details}

We used GAUSSIAN 09 package [56] to perform all the calculations at B3LYP /6-31G(d,p). For Fe atoms the LANL2DZ basis set has been used. The zero-point and thermal corrections were also considered to calculate binding, solvation and activation energies. The transition states have been checked to possess only one imaginary frequency. Polarized continuum model (PCM) was employed for the evaluation of implicit solvent effects [57, 58].

The Chemical reactivity and stability were examined using quantum descriptors. If $I=-E_{H O M O}$ and $A=-E_{L U M O}$ are the ionization potential and the electron affinity, then the global hardness $(\eta)$ is defined by Eq. (1):

$$
\eta=(I-A) / 2 \text {. }
$$

The electrophilicity index $(\omega)$ has been evaluated by Eq. (2) [59]:

$$
\omega=(I+A)^{2} / 4 \eta \text {. }
$$




\section{Results and discussion}

\subsection{Nonbonded interactions}

Tirapazamine (TPZ) is an anticancer drug that has four important functional groups $\left(\mathrm{NH}_{2}\right.$ and $\mathrm{NO} 1, \mathrm{NO} 2$ and $\mathrm{N}$ groups as shown in Fig. 1. Fig. 1 shows the optimized structures of TPZ and magnetic nanoparticle (MNP: $\mathrm{Fe}_{6}(\mathrm{OH})_{18}\left(\mathrm{H}_{2} \mathrm{O}\right)_{6}$ ring cluster model [60]). This model has been developed for magnetite $\left(\mathrm{Fe}_{3} \mathrm{O}_{4}\right)$ and maghemite $(\gamma-$ $\mathrm{Fe}_{2} \mathrm{O}_{3}$ ) nanoparticles, which are widely used in drug delivery. The reason is related to the superparamagnetic properties of these particles, which can be directed to the cancerous tissue by applying an external magnetic field [61,62]. The interactions between magnetic nanoparticle (MNP) and TPZ through $\mathrm{NH}_{2}$ (MNP/TPZ1) and N-oxide 1 (MNP/TPZ2), $\mathrm{N}$-oxide 2 (MNP/TPZ3) and intraring N-atom (MNP/TP4) groups in aqueous solution have been illustrated in Fig. 1.

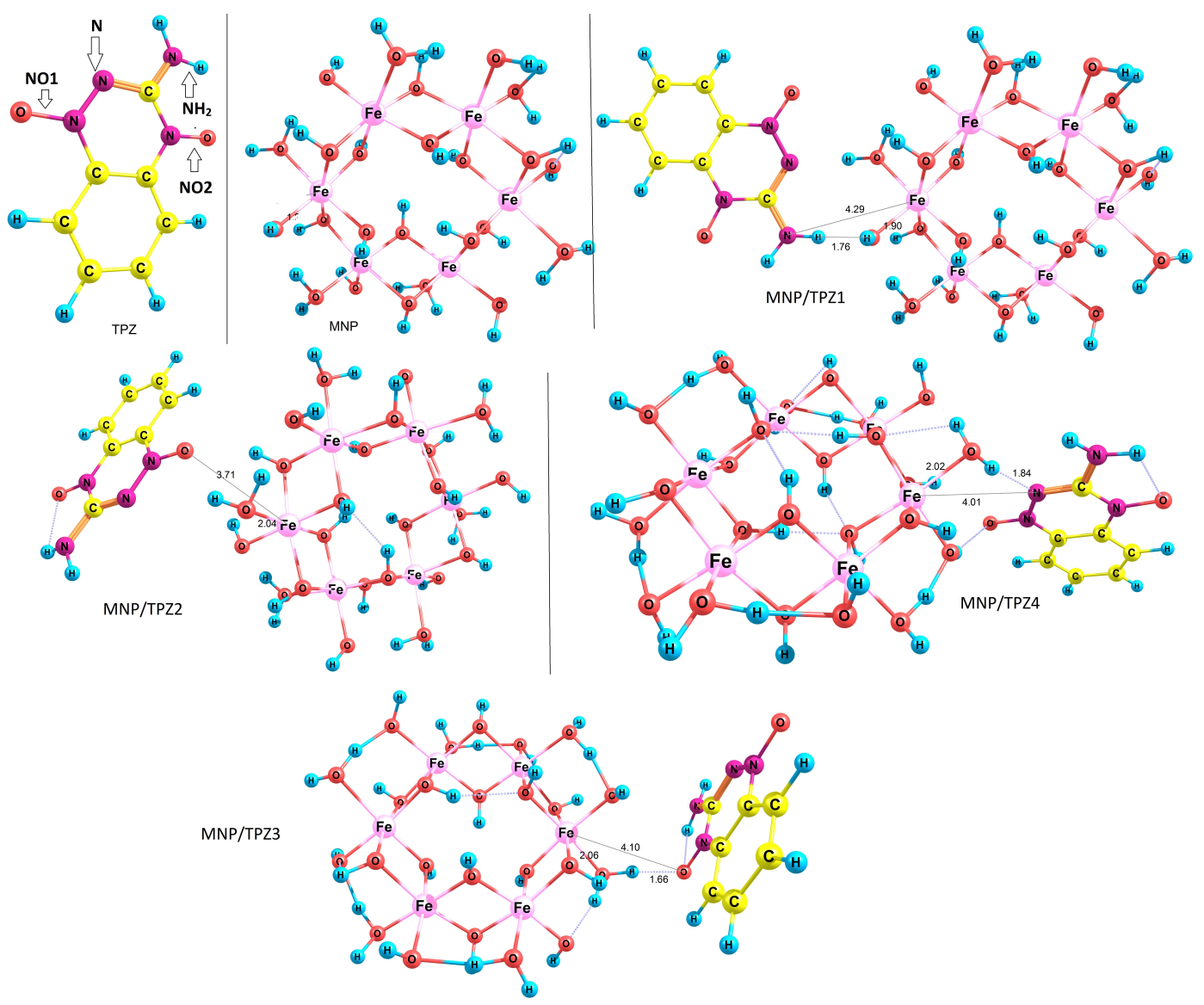

FIG. 1. Optimized structures of TPZ, MNP and MNP/TPZ1-4

For the binding energies $(\Delta E)$, we have (Table 1):

$$
\Delta E=E_{M N P / T P Z 1-4}-\left(E_{M N P}+E_{T P Z}\right),
$$

where $E$ is the sum of electronic and zero-point energies. The negative binding energies in both phases indicate that the drug absorption on the MNP carrier is thermodynamically desirable. Also, MNP/TPZ1 and MNP/TPZ4 are more stable than MNP/TPZ2 and MNP/TPZ3 in both phases.

Table 1 also represents $E_{g}$ (energy difference between LUMO and HOMO), $\omega$ and $\eta$ for all configurations. $E_{g}$ and $\eta$ are indicators to identify more stable structures. These two quantities of MNP/TPZ1 and MNP/TPZ4 have greater amounts than MNP/TPZ2 and MNP/TPZ3. Also, $\eta$ and $E_{g}$ of TPZ are higher than those of MNP/TPZ1-4, indicating the reactivity of TPZ increases in drug-carrier systems. This is important because it raises the possibility of a reaction between the drug and the carrier in appropriate conditions, which will be discussed in the next section. An increase in $\omega$ of TPZ in the drug-carrier systems indicates that TPZ acts as an electron acceptor. 
TABLE 1. Binding energies $\left(\mathrm{kJ} \mathrm{mol}^{-1}\right)$ and quantum molecular descriptors $(\mathrm{eV})$ of calculated structures

\begin{tabular}{|c|c|c|c|c|c|c|}
\hline Species & $\boldsymbol{E}_{\text {НОМо }}$ & $E_{L U M O}$ & $E_{g}$ & $\eta$ & $\omega$ & $\Delta E$ \\
\hline & & \multicolumn{3}{|c|}{ Solution phase (water) } & & \\
\hline TPZ & -5.54 & -2.62 & 2.92 & 1.46 & 5.70 & \\
\hline MNP & -5.58 & -4.48 & 1.10 & 0.55 & 22.95 & \\
\hline MNP/TPZ1 & -5.55 & -4.42 & 1.13 & 0.56 & 22.07 & -11.73 \\
\hline MNP/TPZ2 & -5.56 & -4.52 & 1.04 & 0.52 & 24.42 & -5.09 \\
\hline MNP/TPZ3 & -5.53 & -4.43 & 1.10 & 0.55 & 22.49 & -6.26 \\
\hline \multirow[t]{2}{*}{ MNP/TPZ4 } & -5.67 & -4.56 & 1.11 & 0.56 & 23.49 & -12.54 \\
\hline & & \multicolumn{3}{|c|}{ Gas phase } & & \\
\hline TPZ & -5.39 & -2.52 & 2.87 & 1.44 & 5.45 & \\
\hline MNP & -5.41 & -4.36 & 1.05 & 0.53 & 22.68 & \\
\hline MNP/TPZ1 & -5.49 & -4.42 & 1.07 & 0.53 & 23.00 & -31.41 \\
\hline MNP/TPZ2 & -5.37 & -4.40 & 0.97 & 0.48 & 24.68 & -14.14 \\
\hline MNP/TPZ3 & -5.35 & -4.30 & 1.05 & 0.53 & 22.19 & -15.77 \\
\hline MNP/TPZ4 & -5.39 & -4.25 & 1.14 & 0.57 & 20.46 & -32.76 \\
\hline
\end{tabular}

\subsection{Covalent functionalization}

One possibility of forming a covalent bond between the drug and the carrier is to replace the surface hydroxyl groups of the magnetic nanoparticle with the drug. In this mechanism $\left(\mathrm{NH}_{2}\right.$ mechanism) the amino group of TPZ transfers a hydrogen to the hydroxyl group of MNP so that by leaving a $\mathrm{H}_{2} \mathrm{O}$ molecule, the drug bonds to the $\mathrm{Fe}$ atom and therefore, product MNPTPZ1/ $\mathrm{H}_{2} \mathrm{O}$ is produced (Fig. 2). Fig. 3 shows the optimized structure of product MNPTPZ1/ $\mathrm{H}_{2} \mathrm{O}$.
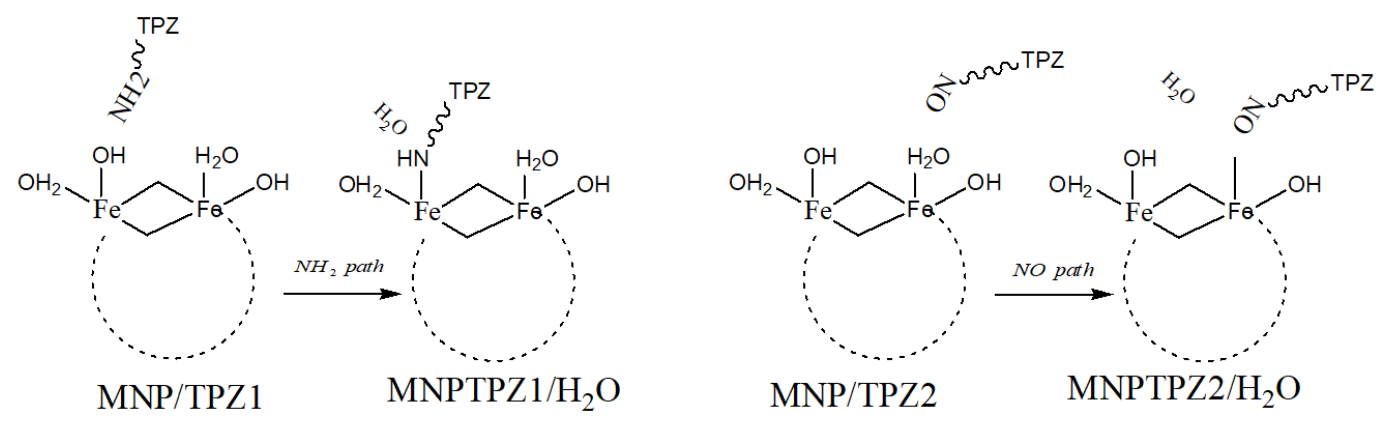

FIG. 2. $\mathrm{NH}_{2}$ and $\mathrm{NO}$ mechanisms

The transition state of this mechanism (TS1) was obtained by Quadratic Synchronous Transit (QST3) method and presented in Fig. 4. Changes in the important bond lengths have been shown in Fig. 1 (reactant MNP/TPZ1), Fig. 3 (product MNPTPZ1/ $\mathrm{H}_{2} \mathrm{O}$ ) and Fig. 4 (TS1).

Relative energies (Gibbs free energy $\left(\Delta G^{\ddagger}\right)$, activation enthalpy $\left(\Delta H^{\ddagger}\right)$ and activation energy $\left(E_{a}\right)$ ) for reactants, products and transition states have been presented in Table 2. The energy values of the product MNPTPZ1/ $\mathrm{H}_{2} \mathrm{O}$ indicate that the process is exothermic $(\Delta H<0)$ and spontaneous $(\Delta G<0) . E_{a}, \Delta H^{\ddagger}$ and $\Delta G^{\ddagger}$ for $\mathrm{NH}_{2}$ mechanism are $103.66,102.71$ and $116.82 \mathrm{~kJ} \mathrm{~mol}^{-1}$, respectively (Table 2).

The other reactions (NO1 and $\mathrm{NO} 2$ mechanisms) have been illustrated in Fig. 2. In these reactions surface $\mathrm{H}_{2} \mathrm{O}$ molecules of MNT are substituted by NO functional groups of TPZ to produce MNPTPZ2/ $\mathrm{H}_{2} \mathrm{O}$ and MNPTPZ3/ $\mathrm{H}_{2} \mathrm{O}$. The optimized structures of products MNPTPZ2/ $\mathrm{H}_{2} \mathrm{O}$ and MNPTPZ3/ $\mathrm{H}_{2} \mathrm{O}$ are shown in Fig. 3. 

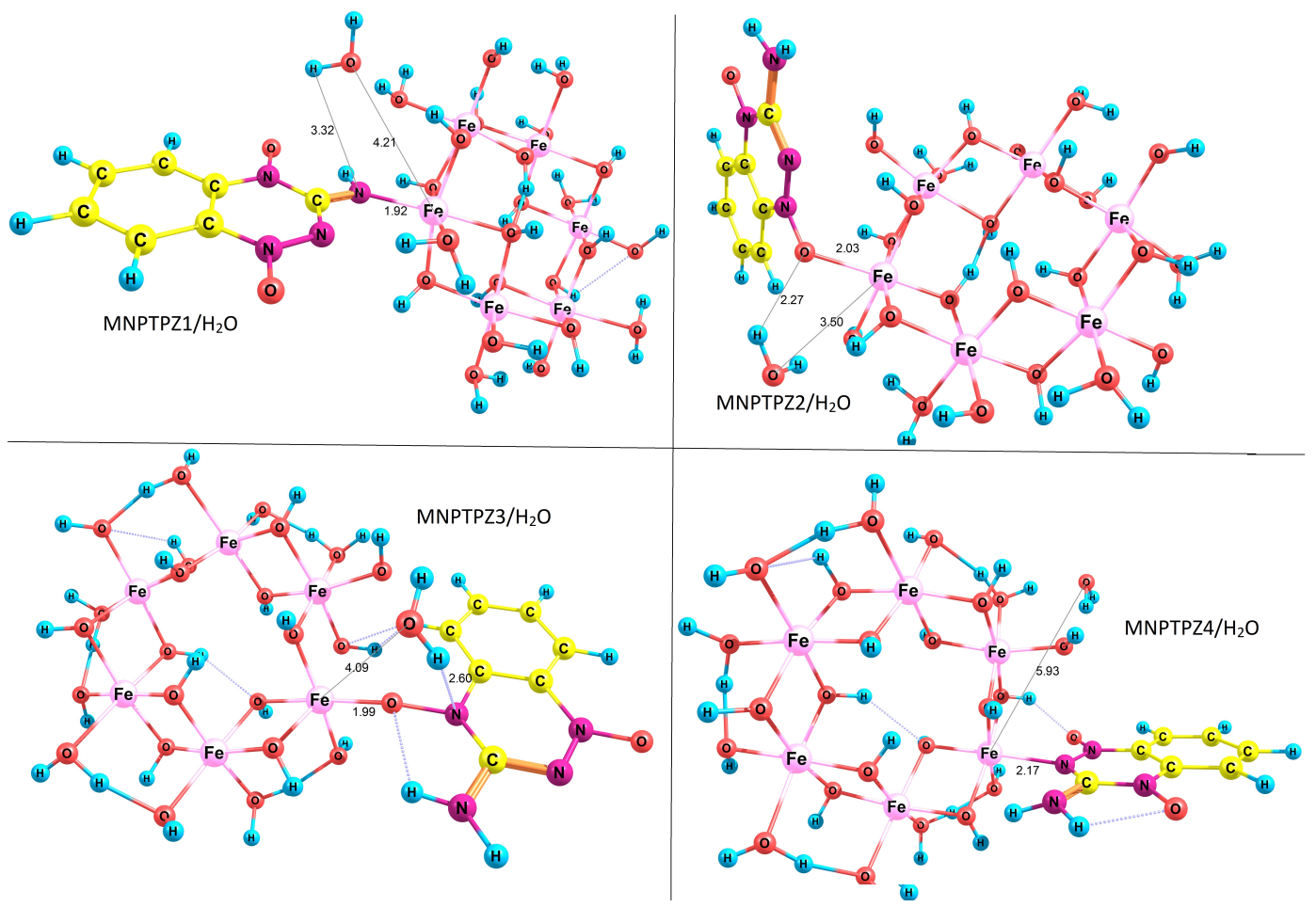

FIG. 3. Optimized structures of MNPTPZ1-4/ $\mathrm{H}_{2}$

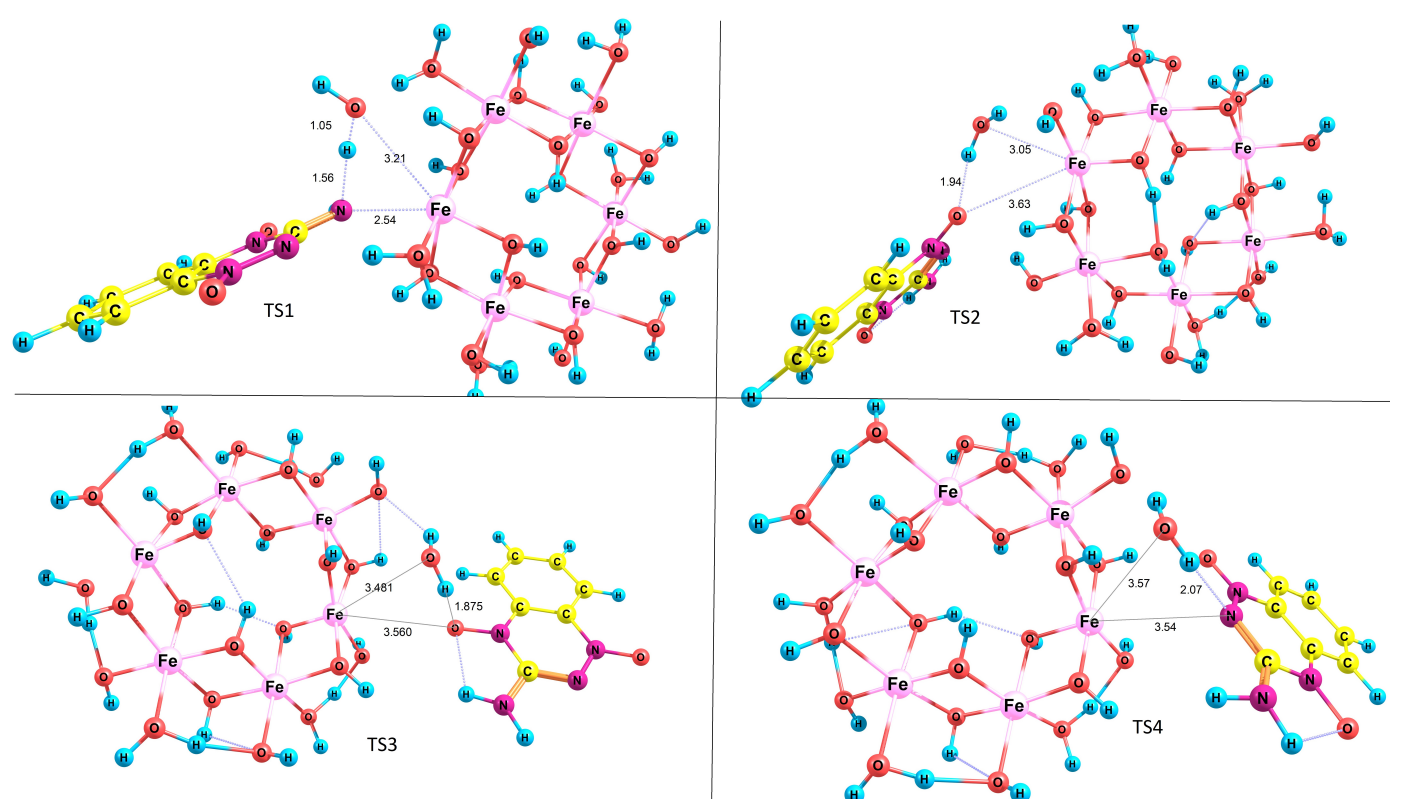

FIG. 4. Optimized structures of TS1-4 
TABLE 2. Relative energies $\left(\mathrm{kJ} \mathrm{mol}^{-1}\right)$ in $\mathrm{NH} 2$ and NO mechanisms

\begin{tabular}{|c|c|c|c|}
\hline Species & $\mathbf{E}$ & $\mathbf{H}$ & $\mathbf{G}$ \\
\hline & \multicolumn{3}{|c|}{$\mathrm{NH}_{2}(\mathrm{OH})$ mechanism } \\
\hline MNP/TPZ1 & 0.00 & 0.00 & 0.00 \\
\hline TS1 & 103.66 & 102.71 & 116.82 \\
\hline \multirow[t]{2}{*}{$\mathrm{MNPTPZ1} / \mathrm{H}_{2} \mathrm{O}$} & -16.67 & -21.70 & -5.34 \\
\hline & \multicolumn{3}{|c|}{ NO1 mechanism } \\
\hline MNP/TPZ2 & 0.00 & 0.00 & 0.00 \\
\hline TS2 & 38.89 & 44.10 & 51.74 \\
\hline \multirow[t]{2}{*}{ MNPTPZ2/ $\mathrm{H}_{2} \mathrm{O}$} & -5.88 & -11.51 & -2.28 \\
\hline & \multicolumn{3}{|c|}{ NO2 mechanism } \\
\hline MNP/TPZ3 & 0.00 & 0.00 & 0.00 \\
\hline TS3 & 37.22 & 43.08 & 50.91 \\
\hline \multirow[t]{2}{*}{ MNPTPZ3/ $\mathrm{H}_{2} \mathrm{O}$} & -7.60 & -14.03 & -3.26 \\
\hline & \multicolumn{3}{|c|}{$\mathrm{N}$ mechanism } \\
\hline MNP/TPZ3 & 0.00 & 0.00 & 0.00 \\
\hline TS4 & 65.47 & 69.84 & 77.27 \\
\hline \multirow[t]{2}{*}{$\mathrm{MNPTPZ} 3 / \mathrm{H}_{2} \mathrm{O}$} & 9.43 & 3.39 & 12.46 \\
\hline & \multicolumn{3}{|c|}{$\mathrm{NH}_{2}\left(\mathrm{H}_{2} \mathrm{O}\right)$ mechanism } \\
\hline MNP/TPZ1+ & 0.00 & 0.00 & 0.00 \\
\hline TS1+ & 81.31 & 87.99 & 94.69 \\
\hline $\mathrm{MNPTPZ} 1+/ \mathrm{H}_{2} \mathrm{O}$ & 11.02 & 6.06 & 13.80 \\
\hline
\end{tabular}

Using reactants MNP/TPZ2 and MNPTPZ3/ $\mathrm{H}_{2} \mathrm{O}$ and products MNPTPZ2/ $\mathrm{H}_{2} \mathrm{O}$ and MNPTPZ3/ $\mathrm{H}_{2} \mathrm{O}$, the transition states of NO pathways (Fig. 4) were found (TS2 and TS3). $E_{a}, \Delta H^{\ddagger}$ and $\Delta G^{\ddagger}$ of NO1 mechanism (NO2 mechanism) are 38.89 (37.22), 44.10 (43.08) and $51.74 \mathrm{~kJ} \mathrm{~mol}^{-1}\left(50.91 \mathrm{~kJ} \mathrm{~mol}^{-1}\right)$, respectively (Table 2). Similar to the previous reaction, these reactions are also spontaneous and exothermic.

The $\mathrm{N}$ mechanism is similar to NO mechanism. In this mechanism, the surface $\mathrm{H}_{2} \mathrm{O}$ molecule of MNP is substituted by the intraring $\mathrm{N}$-atom functional group of TPZ to produce product MNPTPZ4/ $\mathrm{H}_{2} \mathrm{O}$ (Fig. 3). Using MNP/TPZ4 and MNPTPZ4 $/ \mathrm{H}_{2} \mathrm{O}$, the transition state of N mechanism (Fig. 4) was optimized (TS4). $E_{a}, \Delta H^{\ddagger}$ and $\Delta G^{\ddagger}$ of N mechanism are $65.47,69.74$ and $77.27 \mathrm{~kJ} \mathrm{~mol}^{-1}$, respectively (Table 2). Another possibility is to consider a mechanism similar to $\mathrm{NO}$ and $\mathrm{N}$ mechanisms for $\mathrm{NH}_{2}$ functional group $\left(\mathrm{NH}_{2}+\right.$ mechanism). Fig. 5 shows the reactant (MNP/TPZ1+), product (MNPTPZ1+/ $\mathrm{H}_{2} \mathrm{O}$ ) and transition state (TS1+) for this reaction. $E_{a}, \Delta H^{\ddagger}$ and $\Delta G^{\ddagger}$ of $\mathrm{NH}_{2}+$ mechanism are $81.31,87.99$ and $94.69 \mathrm{~kJ} \mathrm{~mol}^{-1}$, respectively (Table 2). The latter two mechanisms are endothermic and nonspontaneous (endergonic reactions), unlike the previous ones.

The first reaction product (MNPTPZ1/ $\mathrm{H}_{2} \mathrm{O}$ ) has more negative energy (is more stable) than the other reaction products, therefore, MNPTPZ1/ $\mathrm{H}_{2} \mathrm{O}$ is the thermodynamic product. On the other hand, the values of activation parameters related to the $\mathrm{NO} 1$ and $\mathrm{NO} 2$ mechanisms are lower than those of the $\mathrm{NH}_{2}, \mathrm{~N}$ and $\mathrm{NH}_{2}+$ mechanisms. For example, the activation energy of the second mechanism (NO1) is lower than the former $\left(\mathrm{NH}_{2}\right)$ by $64.79 \mathrm{~kJ} \mathrm{~mol}^{-1}$. So, MNPTPZ2/ $\mathrm{H}_{2} \mathrm{O}$ and MNPTPZ3/ $\mathrm{H}_{2} \mathrm{O}$ are kinetic products. Increasing the temperature (for example, using ultrasonic irradiation) will increase the contribution of the product MNPTPZ1/ $\mathrm{H}_{2} \mathrm{O}\left(\mathrm{NH}_{2}\right.$ mechanism) which has higher activation energy due to the proton transfer from the amino group of TPZ to the hydroxyl group of MNP. 


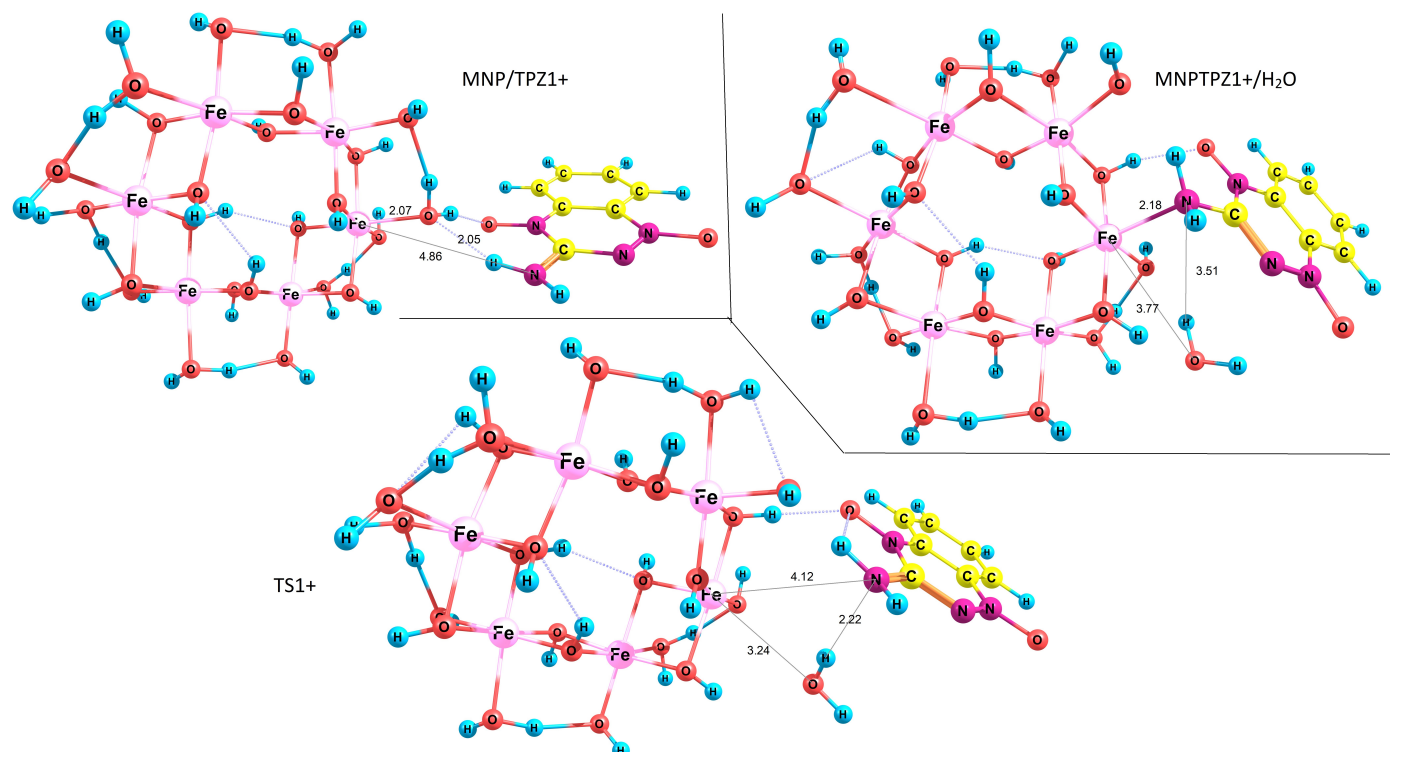

FIG. 5. Optimized structures of MNP/TPZ1+, MNPTPZ1+/ $\mathrm{H}_{2} \mathrm{O}$ and TS1+

\section{Conclusion}

Four noncovalent interactions related to the orientations of the $\mathrm{NH}_{2}$ (MNP/TPZ1), NO (MNP/TPZ2-3) and intraring N-atom (MNP/TP4) functional groups of tirapazamine anticancer drug (TPZ) towards the magnetic nanocarrier $\mathrm{Fe}_{6}(\mathrm{OH})_{18}\left(\mathrm{H}_{2} \mathrm{O}\right)_{6}(\mathrm{MNP})$ were investigated using a quantum mechanical approach (DFT). The negative values of binding energies and quantum molecular descriptor such global hardness and HOMO-LUMO energy gap indicate all interactions in gas phase and aqueous solution are energetically suitable and MNP/TPZ1 and MNP/TPZ4 are more stable than MNP/TPZ2-3.

As the temperature increases, a covalent bond can be formed between the drug and the carrier. Four mechanisms thorough $\mathrm{NH}_{2}\left(\mathrm{NH}_{2}\right.$ mechanism), $\mathrm{NO}$ (NO mechanisms) and intraring $\mathrm{N}$-atom ( $\mathrm{N}$ mechanism) functional groups have been examined. It was specified that the products of the NO mechanisms have lower activation energies than the others but are more unstable than that of $\mathrm{NH}_{2}$ mechanism (kinetic product). Therefore, the product of $\mathrm{NH}_{2}$ mechanism is a thermodynamic product.

\section{References}

[1] Lu A.H., Salabas E.e.L., Schüth F. Magnetic nanoparticles: synthesis, protection, functionalization, and application. Angew. Chem. Int. Ed., 2007, 46, P. 1222-1244.

[2] Jun Y.-w., Seo J.-w., Cheon J. Nanoscaling laws of magnetic nanoparticles and their applicabilities in biomedical sciences. Acc. Chem. Res., 2008, 41, P. 179-189.

[3] Goll D. Magnetism of nanostructured materials for advanced magnetic recording. Int. J. Mater. Res., 2009, 100, P. 652-662.

[4] Albadi Y., Martinson K.D., et al. Synthesis of $\mathrm{GdFeO}_{3}$ nanoparticles via low-temperature reverse co-precipitation: the effect of strong agglomeration on the magnetic behavior. Nanosystems: Phys. Chem. Math., 2020, 11, P. 252-259.

[5] Galli M., Guerrini A., et al. Superparamagnetic iron oxide nanoparticles functionalized by peptide nucleic acids. RSC Adv., 2017, 7, P. 1550015512.

[6] Neamtu J., Verga N. Magnetic nanoparticles for magneto-resonance imaging and targeted drug delivery. Dig. J. Nanomater. Biostruct., 2011, 6. P. 969-978.

[7] Liu Y.-L., Chen D., Shang P., Yin D.-C. A review of magnet systems for targeted drug delivery. J. Controlled Release, 2019, 302, P. 90-104.

[8] Pankhurst Q.A., Connolly J., Jones S.K., Dobson J. Applications of magnetic nanoparticles in biomedicine. J. Phys. D: Appl. Phys., 2003, 36, R167.

[9] Arruebo M., Fernández-Pacheco R., Ibarra M.R., Santamaría J. Magnetic nanoparticles for drug delivery. Nano today, 2007 , b, P. $22-32$.

[10] Akbarzadeh A., Samiei M., Davaran S. Magnetic nanoparticles: preparation, physical properties, and applications in biomedicine. Nanoscale Res. Lett., 2012, 7, 144.

[11] Bi H., Han X. Magnetic field triggered drug release from lipid microcapsule containing lipid-coated magnetic nanoparticles. Chem. Phys. Lett., 2018, 706, P. 455-460.

[12] Roohi R., Emdad H., Jafarpur K. A comprehensive study and optimization of magnetic nanoparticle drug delivery to cancerous tissues via external magnetic field. J. Test. Eval., 2019, 47, P. 681-703.

[13] Dobson J. Magnetic nanoparticles for drug delivery. Drug Dev. Res., 2006, 67, P. 55-60.

[14] Namdeo M., Saxena S., et al. Magnetic nanoparticles for drug delivery applications. J. Nanosci. Nanotechnol., 2008,8 , P. 3247-3271. 
[15] Hossen S., Hossain M.K., et al. Smart nanocarrier-based drug delivery systems for cancer therapy and toxicity studies: A review. J. Adv. Res., 2019, 15, P. 1-18.

[16] Ostroushko A.A., Gagarin I.y.D., Danilova I.G., Gette I.F. The use of nanocluster polyoxometalates in the bioactive substance delivery systems. Nanosystems: Phys. Chem. Math., 2019, 10, P. 318-349.

[17] Shanmuganathan R., Edison T.N.J.I., et al. Chitosan nanopolymers: an overview of drug delivery against cancer. Int. J. Biol. Macromol., 2019, 130, P. 727-736.

[18] Popova N., Popov A., Shcherbakov A., Ivanov V. Layer-by-layer capsules as smart delivery systems of $\mathrm{CeO}_{2}$ nanoparticle-based theranostic agents. Nanosystems: Phys. Chem. Math., 2017, 8, P. 282-289.

[19] Ramasamy T., Ruttala H.B., et al. Smart chemistry-based nanosized drug delivery systems for systemic applications: a comprehensive review. J. Controlled Release, 2017, 258, P. 226-253.

[20] Pennock G.D., Dalton W.S., et al. Systemic toxic effects associated with high-dose verapamil infusion and chemotherapy administration. $J$. Natl. Cancer Inst., 1991, 83, P. 105-110.

[21] Lindley C., McCune J.S., et al. Perception of chemotherapy side effects cancer versus noncancer patients. Cancer pract., 1999 , 7, P. 59-65.

[22] Arias J.L., Gallardo V., Ruiz M.A., Delgado Á.V. Magnetite/poly (alkylcyanoacrylate)(core/shell) nanoparticles as 5-Fluorouracil delivery systems for active targeting. Eur. J. Pharm. Biopharm., 2008, 69, P. 54-63.

[23] Wagstaff A.J., Brown S.D., et al. Cisplatin drug delivery using gold-coated iron oxide nanoparticles for enhanced tumour targeting with external magnetic fields. Inorg. Chim. Acta, 2012, 393, P. 328-333.

[24] Cengelli F., Grzyb J.A., et al. Surface-Functionalized Ultrasmall Superparamagnetic Nanoparticles as Magnetic Delivery Vectors for Camptothecin. ChemMedChem, 2009, 4, P. 988-997.

[25] Zhu K., Deng Z., et al. Photoregulated cross-linking of superparamagnetic iron oxide nanoparticle (spion) loaded hybrid nanovectors with synergistic drug release and magnetic resonance (MR) imaging enhancement. Macromolecules, 2017, 50, P. 1113-1125.

[26] Kohler N., Sun C., et al. Methotrexate-Immobilized Poly (ethylene glycol) Magnetic Nanoparticles for MR Imaging and Drug Delivery. Small, 2006, 2, P. 785-792.

[27] Majd M.H., Asgari D., et al. Tamoxifen loaded folic acid armed PEGylated magnetic nanoparticles for targeted imaging and therapy of cancer. Colloids and Surfaces B: Biointerfaces, 2013, 106, P. 117-125.

[28] Chen Y.C., Lee W.F., Tsai H.H., Hsieh W.Y. Paclitaxel and iron oxide loaded multifunctional nanoparticles for chemotherapy, fluorescence properties, and magnetic resonance imaging. J. Biomed. Mater. Res. A, 2012, 100, P. 1279-1292.

[29] Depalo N., Iacobazzi R.M., et al. Sorafenib delivery nanoplatform based on superparamagnetic iron oxide nanoparticles magnetically targets hepatocellular carcinoma. Nano Research, 2017, 10, P. 2431-2448.

[30] Kim D.H., Guo Y., et al. Temperature-Sensitive Magnetic Drug Carriers for Concurrent Gemcitabine Chemohyperthermia. Adv. Healthc. Mater., 2014, 3, P. 714-724.

[31] Dorniani D., bin Hussein M.Z., et al. Preparation and characterization of 6-mercaptopurine-coated magnetite nanoparticles as a drug delivery system. Drug Des. Devel. Ther, 2013, 7, 1015.

[32] Krukemeyer M.G., Krenn V., Jakobs M., Wagner W. Mitoxantrone-iron oxide biodistribution in blood, tumor, spleen, and liver-magnetic nanoparticles in cancer treatment. J. Surg. Res., 2012, 175, P. 35-43.

[33] Sood A., Arora V., et al. Multifunctional gold coated iron oxide core-shell nanoparticles stabilized using thiolated sodium alginate for biomedical applications. Mater. Sci. Eng.: C, 2017, 80, P. 274-281.

[34] Hemalatha T., Prabu P., Gunadharini D.N., Gowthaman M.K. Fabrication and characterization of dual acting oleyl chitosan functionalised iron oxide/gold hybrid nanoparticles for MRI and CT imaging. Int. J. Biol. Macromol., 2018, 112, P. $250-257$.

[35] Santra S., Tapec R., et al. Synthesis and characterization of silica-coated iron oxide nanoparticles in microemulsion: the effect of nonionic surfactants. Langmuir, 2001, 17, P. 2900-2906.

[36] Khashan K.S., Sulaiman G.M., Mahdi R. Preparation of iron oxide nanoparticles-decorated carbon nanotube using laser ablation in liquid and their antimicrobial activity. Artif. Cells Nanomed. Biotechnol., 2017, 45, P. 1699-1709.

[37] Kim D., Zhang Y., et al. Synthesis and characterization of surfactant-coated superparamagnetic monodispersed iron oxide nanoparticles. $J$. Magn. Magn. Mater., 2001, 225, P. 30-36.

[38] Hou X., Zhang X., et al. Surface-enhanced Raman scattering of C60 on co-modified substrate of Fe3O4 and Au nanoparticles. Chem. Phys., 2010, 372, P. 1-5.

[39] Emtiazi G., Zohrabi T., et al. Covalent diphenylalanine peptide nanotube conjugated to folic acid/magnetic nanoparticles for anti-cancer drug delivery. Journal of Drug Delivery Science and Technology, 2017, 41, P. 90-98.

[40] Jiang S., Eltoukhy A.A., et al. Lipidoid-coated iron oxide nanoparticles for efficient DNA and siRNA delivery. Nano Lett., 2013, 13, P. 10591064.

[41] Sharifabad M.E., Mercer T., Sen T. Drug-loaded liposome-capped mesoporous core-shell magnetic nanoparticles for cellular toxicity study. Nanomedicine, 2016, 11, P. 2757-2767.

[42] Tassa C., Shaw S.Y., Weissleder R. Dextran-coated iron oxide nanoparticles: a versatile platform for targeted molecular imaging, molecular diagnostics, and therapy. Acc. Chem. Res., 2011, 44, P. 842-852.

[43] Kievit F.M., Veiseh O., et al. PEI-PEG-chitosan-copolymer-coated iron oxide nanoparticles for safe gene delivery: synthesis, complexation, and transfection. Adv. Funct. Mater., 2009, 19, P. 2244-2251.

[44] Lee H., Lee E., et al. Antibiofouling polymer-coated superparamagnetic iron oxide nanoparticles as potential magnetic resonance contrast agents for in vivo cancer imaging. J. Am. Chem. Soc., 2006, 128, P. 7383-7389.

[45] McBain S., Yiu H., El Haj A., Dobson J. Polyethyleneimine functionalized iron oxide nanoparticles as agents for DNA delivery and transfection. J. Mater. Chem., 2007, 17, P. 2561-2565.

[46] Shabani Z., Morsali A., Bozorgmehr M.R., Beyramabadi S.A. Quantum chemical modeling of iron oxide magnetic nanoparticles functionalized with cytarabine. Chem. Phys. Lett., 2019, 719, P. 12-21.

[47] Lotfi M., Morsali A., Bozorgmehr M.R. Comprehensive quantum chemical insight into the mechanistic understanding of the surface functionalization of carbon nanotube as a nanocarrier with cladribine anticancer drug. Appl. Surf. Sci., 2018, 462, P. 720-729.

[48] Naghavi F., Morsali A., Bozorgmehr M.R. Molecular mechanism study of surface functionalization of silica nanoparticle as an anticancer drug nanocarrier in aqueous solution. J. Mol. Liq., 2019, 282, P. 392-400. 
[49] Hadi L., Ali M., Momen H.M. The prediction of COOH functionalized carbon nanotube application in melphalan drug delivery. Nanosystems: Phys. Chem. Math., 2019, 10, P. 438-446.

[50] Najafi M., Morsali A., Bozorgmehr M.R. DFT study of SiO 2 nanoparticles as a drug delivery system: structural and mechanistic aspects. Struct. Chem., 2018, P. 1-12.

[51] Nasrabadi M., Beyramabadi S.A., Morsali A. Surface functionalization of chitosan with 5-nitroisatin. Int. J. Biol. Macromol., 2020, 147, P. 534-546.

[52] Bokarev A., Plastun I. Possibility of drug delivery due to hydrogen bonds formation in nanodiamonds and doxorubicin: molecular modeling. Nanosystems: Phys. Chem. Math., 2018, 9, P. 370-377.

[53] Khoshbayan B., Morsali A., Bozorgmehr M.R. Structural and Electronic Properties of Cyclic Peptide-gold Nanoparticle as a Drug Delivery System. Chinese J. Struc. Chem., 2019, 38, P. 566-580.

[54] Denny W.A. Prospects for hypoxia-activated anticancer drugs. Curr. Med. Chem. Anticancer Agents, 2004, 4, P. $395-399$.

[55] Zeman E.M., Brown J.M., et al. SR-4233: a new bioreductive agent with high selective toxicity for hypoxic mammalian cells. Int. J. Radiat. Oncol. Biol. Phys., 1986, 12, P. 1239-1242.

[56] Frisch M., Trucks G.,et al. G09 Gaussian Inc. Gaussian 09, revision B.01. Gaussian, Inc., Wallingford, CT, 2009.

[57] Cammi R., Tomasi J. Remarks on the use of the apparent surface charges (ASC) methods in solvation problems: Iterative versus matrixinversion procedures and the renormalization of the apparent charges. J. Comput. Chem., 1995, 16, P. 1449-1458.

[58] Tomasi J., Persico M. Molecular interactions in solution: an overview of methods based on continuous distributions of the solvent. Chem. Rev., 1994, 94, P. 2027-2094.

[59] Parr R.G., Szentpaly L.v., Liu S. Electrophilicity index. J. Am. Chem. Soc., 1999, 121, P. 1922-1924.

[60] Jayarathne L., Ng W.J., et al. Fabrication of succinic acid- $\gamma-\mathrm{Fe}_{2} \mathrm{O}_{3}$ nano core-shells. Colloids Surf. A, 2012 , 403, P. 96-102.

[61] Douziech-Eyrolles L., Marchais H., et al. Nanovectors for anticancer agents based on superparamagnetic iron oxide nanoparticles. Int. J. Nanomedicine, 2007, 2, P. 541-550.

[62] Mahmoudi M., Sant S., et al. Superparamagnetic iron oxide nanoparticles (SPIONs): development, surface modification and applications in chemotherapy. Adv. Drug Deliv. Rev., 2011, 63, P. 24-46. 